\title{
Microwave absorption behaviour of MWCNT based nanocomposites in $\mathrm{X}$-band region
}

\author{
P. Bhattacharya, S. Sahoo, C. K. Das* \\ Materials Science centre, Indian Institute of technology, 721302 Kharagpur, West Bengal, India
}

Received 26 July 2012; accepted in revised form 19 October 2012

\begin{abstract}
Multiwall carbon nanotube (MWCNT) based nanocomposites were prepared by a two-step process. Firstly, titanium dioxide $\left(\mathrm{TiO}_{2}\right)$ coated MWCNT was prepared via sol-gel technique. In the second step, the acid modified MWCNTs were dispersed in the thermoplastic polyurethane matrix by solution blending process. Characterizations of the nanocomposites were done by X-ray diffraction analysis, X-ray photoelectron spectroscopy, Scanning Electron Microscopy, Transmission Electron Microscopy and Energy-dispersive X-ray spectroscopy. Microwave absorption studies of the nanocomposites were carried out in X-band region. The microwave absorption result was discussed with the help of complex permittivity and permeability of the prepared radar absorbing material (RAM). The result showed superior microwave absorption property of the composite containing both $\mathrm{TiO}_{2}$ coated MWCNT and magnetite $\left(\mathrm{Fe}_{3} \mathrm{O}_{4}\right)$. This result is due to the effective absorption of both electrical and magnetic components of the microwave. RAM-MW, RAM-Ti, RAM-Ti@MW and RAM$\mathrm{Ti} @ \mathrm{MW} / \mathrm{Fe}$ and showed the maximum reflection loss of $-16.03 \mathrm{~dB}$ at $10.99 \mathrm{GHz},-8.4 \mathrm{~dB}$ at $12.4 \mathrm{GHz},-36.44 \mathrm{~dB}$ at $12.05 \mathrm{GHz}$ and $-42.53 \mathrm{~dB}$ at $10.98 \mathrm{GHz}$ respectively. Incorporation of MWCNT enhanced the thermal stability of the composite which has been confirmed by thermogravimetric analysis.
\end{abstract}

Keywords: nanocomposites, carbon nanotube, permittivity, permeability, microwave absorption

\section{Introduction}

In this modern era, designing and manufacturing of electronic device, which functions in higher frequency range, is a great challenge for the engineers because of the electromagnetic interference (EMI) problems. In defense, use of radar absorbing material (RAM), a material which absorbs microwave radiation in $\mathrm{X}$ band region only, is must to stealth the object by reducing the radar cross section. Therefore, the demand for light weight and effective radar absorbing material, in both commercial and military application, is increasing day to day [1-3]. Scientists are interested in X band region particularly, because most of the Radio Detection and Ranging (RADAR) applications are involved in this region. Many composites based on graphene, graphene oxide, carbon nanotube (CNT) have already been reported on this particular topic due to their great thermal stability, reluctance toward chemical agent, high aspect ratio and excellent electrical conductivity [4-7]. Sometimes, graphene [8] and graphene oxide [9] showed their potentiality as a radar absorbing material over CNT, but the problem is that they are very much uneconomical, and their synthetic approach is not very much fruitful. Hence, CNT and its composite materials are very much attractive for the preparation of RAMs. Yang et al. [10] reported a composite material, made of CNT and polystyrene, which showed maximum reflection loss $(R L)$ of $-19 \mathrm{~dB}$. Qi et al. [11] reported a CNT-paraffin composite that showed $-20 \mathrm{~dB} R L$ at $10.5 \mathrm{GHz}$. The composite prepared with the addition of $20 \mathrm{wt} \%$ of the Fe filled CNTs showed reflection loss of $-11.2 \mathrm{~dB}$ [12]. From past few years, the composite containing

\footnotetext{
*Corresponding author, e-mail: chapal12@yahoo.co.in

(C) BME-PT
} 
both dielectric and magnetic component is a wellconsidered topic in the field of EMI shielding and RAMs [13-18]. As the electromagnetic radiation has both dielectric and magnetic component, so it is obvious that both dielectric and magnetic material is effective for the absorption of microwave radiation. X. Liu et al. [19] reported the hybrid microsphere, Fe-phthalocyanine oligomer $/ \mathrm{Fe}_{3} \mathrm{O}_{4}$ that showed the maximum reflection loss of $-31.1 \mathrm{~dB}$ at 8.6 GHz. Murugan et al. [20] reported the microwave absorbing property of nanosized $\mathrm{CaTiO}_{3} /$ epoxy resin composites where the maximum reflection loss is $-30 \mathrm{~dB}$ at $8.5 \mathrm{GHz}$. X. Zhou et al. [21] also reported the maximum reflection loss of $-18 \mathrm{~dB}$ at $9 \mathrm{GHz}$ for $\mathrm{CNT}-\mathrm{CoFe}_{2} \mathrm{O}_{4}$ nanocomposite, whereas, the maximum reflection loss for $\mathrm{CNT}$ and $\mathrm{CoFe}_{2} \mathrm{O}_{4}$ is $-6 \mathrm{~dB}$ and $-8.3 \mathrm{~dB}$ respectively. Hence, the composite material, in combination with dielectric or magnetic component or both, is always a better microwave absorber than their individual component. In this paper, we have prepared four different nanocomposites and investigated their microwave absorption property in $\mathrm{X}$ band $(8.2-12.4 \mathrm{GHz})$ region. To prepare those nanocomposites, we have used MWCNT, a dielectric material $\left(\mathrm{TiO}_{2}\right)$ and magnetite $\left(\mathrm{Fe}_{3} \mathrm{O}_{4}\right)$ as a magnetic component. Here $\mathrm{TiO}_{2}$ was taken because of its high thermal stability and moderate dielectric constant of 100 [22]. $\mathrm{Fe}_{3} \mathrm{O}_{4}$, a member of spinel family, was taken due to its low toxicity and great stability at high temperature [2324]. $\mathrm{TiO}_{2}$ coated MWCNT is well known for multipurpose applications [25-29]. But to best of our knowledge it has not been reported yet for microwave application. HereTiO 2 coated MWCNT has been prepared by sol-gel process and then both uncoated and $\mathrm{TiO}_{2}$ coated MWCNT was dispersed in a matrix. Thermoplastic polyurethane (TPU) was taken as a polymer matrix for all RAMs due to its flexibility [30].

\section{Experimental work}

\subsection{Materials}

MWCNTs (Guangzhou Jiechuang Trading Co. Ltd., China) having the outer diameter of $20-30 \mathrm{~nm}$ and length of $3-15 \mu \mathrm{m}$ were used as a component for the preparation of nanocomposites. Titanium (IV) n-butoxide was utilised for coating on MWCNT and iso-propanol (Sigma Aldrich, India) was used as a solvent. Tetrahydrofuran $\left(\mathrm{C}_{4} \mathrm{H}_{8} \mathrm{O}\right.$, E. Merck Ltd., India) was used as a solvent for the prepara- tion of RAM. Titanium dioxide $\left(\mathrm{TiO}_{2}\right.$, Loba Chemie Private Limited, India) and magnetite $\left(\mathrm{Fe}_{3} \mathrm{O}_{4}\right.$, Loba Chemie Private Limited, India) used as a nanofiller. Cetyltrimethylammonium bromide (CTAB) has played the role of a surfactant $\left[\left(\mathrm{C}_{16} \mathrm{H}_{33}\right) \mathrm{N}\left(\mathrm{CH}_{3}\right)_{3} \mathrm{Br}\right)$, Loba Chemie Private Limited, India]. All the chemicals and materials were used as purchased without any purification unless specified. The TPU (Lubrizol Advanced Materials, Thermedics TM Inc. Polymer Products, USA) used for developing RAMs belong with commercial medical grade aliphatic, polyether (TecoflexVR EG 80A injection grade). Tecoflex EG 80A (around 35\% of hard segments) has shore hardness of $72 \mathrm{~A}$, specific gravity of 1.04 , and its constituent formulation contains methylene bis (cyclohexyl) diisocyanate (HMDI) as hard segment, and polytetramethylene oxide (PTMO) as soft segment (molecular weight $=1000 \mathrm{~g} / \mathrm{mol}$ ), and chain extender 1, 4-butane di-ol (BD).

\subsection{Preparation of $\mathrm{TiO}_{2}$ coated MWCNT}

The pristine MWCNT has lower dispersibility in solvent and remained unfunctionalised, which is not suitable for further reaction with chemical substance. Hence, to make effective reactant and highly dispersible in solvent, MWCNT was modified by the mixture of $\mathrm{HNO}_{3}$ and $\mathrm{H}_{2} \mathrm{SO}_{4}(3: 1)$ according to the procedure described in [31]. Acid modification generates many oxygenated functional group on the surface of MWCNT. This functionalization assists the interaction between MWCNT and $\mathrm{TiO}_{2}$ particle [32]. In situ coating of acid modified MWCNT was done by titanium(IV) n-butoxide via the sol-gel technique. The process of coating followed the procedure reported by Yuen S. M. et al. [33]. At first, acid modified MWCNT was dispersed in iso-propanol through sonication in presence of a cationic surfactant cetyltrimethylammonium bromide. After that the titanium (IV) n-butoxide was added to this solution and sonicated for $20 \mathrm{~min}$. Then distilled $\mathrm{H}_{2} \mathrm{O}$ was added to it slowly and kept under stirring at room temperature. The stirring was continued for next two days. In presence of $\mathrm{H}_{2} \mathrm{O}$, titanium (IV) nbutoxide converted to its hydrolysed product titanium (IV) hydroxide which may add to the MWCNT surface by forming H-bonds [34]. Finally, the solution was dried at $100^{\circ} \mathrm{C}$ and then it was further annealed at $450^{\circ} \mathrm{C}$. One schematic presentation has been shown in Figure 1 to understand the formation of $\mathrm{TiO}_{2}$ coated MWCNT nanocomposite. 


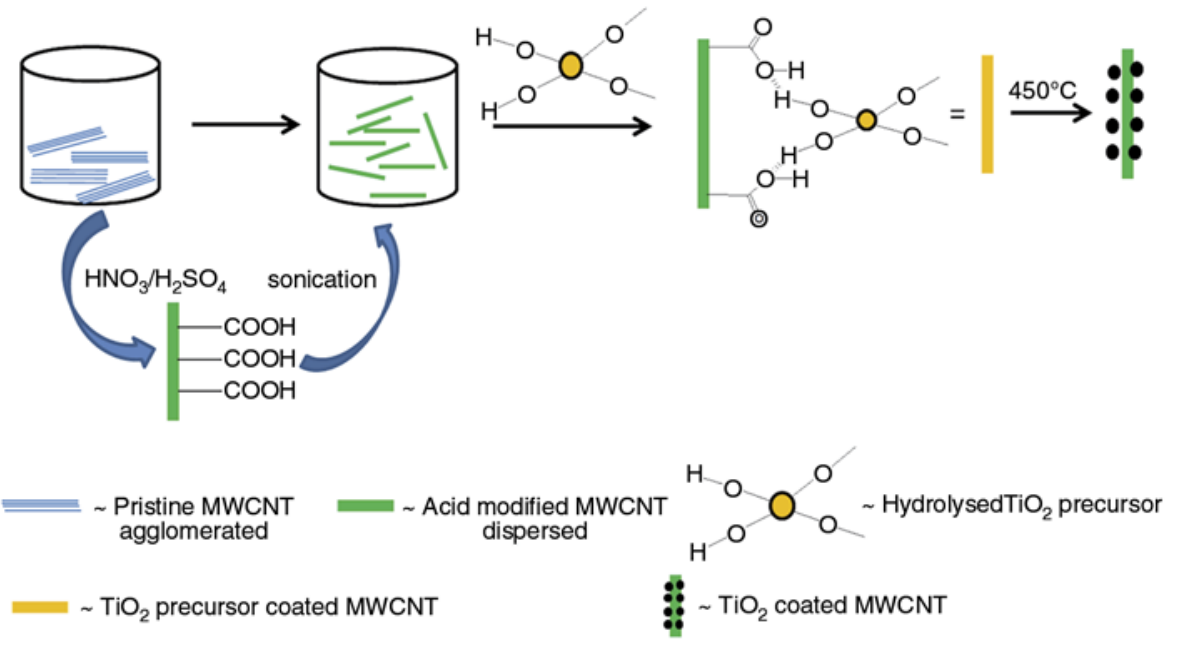

Figure 1. Schematic presentation for the formation of $\mathrm{TiO}_{2}$ coated MWCNT nanocomposite

\subsection{Preparation of nanocomposites}

Four different TPU based nanocomposites were prepared with various combinations of fillers. The composition details for all RAMs were given in Table 1. To prepare the nanocomposites, TPU was dissolved in $200 \mathrm{~mL}$ THF at $60^{\circ} \mathrm{C}$ by stirring it for overnight and then required filler was added to it in desired ratios. After the addition of fillers, the stirring was continued by a mechanical stirrer till the filler becomes fully dispersed in the matrix. After that the mixture was dried at $70^{\circ} \mathrm{C}$ to evaporate the solvent and make the mixture highly concentrated. Then this highly concentrated mixture was poured on a petri dish and heating was continued at $70^{\circ} \mathrm{C}$ for complete drying. After complete drying, the product was treated by compression molding technique at $5 \mathrm{MPa}$ pressure and $170^{\circ} \mathrm{C}$ temperature. Four samples were prepared with $30 \%$ loading of MWCNT, $\mathrm{TiO}_{2}, \mathrm{TiO}_{2}$ coated $\mathrm{MWCNT}$ and $\mathrm{TiO}_{2}$ coated MWCNT (15\%) $+\mathrm{Fe}_{3} \mathrm{O}_{4}(15 \%)$. For the preparation of RAM-Ti@MW/Fe, ball milling technique was used to mix $\mathrm{TiO}_{2}$ coated MWCNT and $\mathrm{Fe}_{3} \mathrm{O}_{4}$. Thickness of the RAM was maintained at $2 \mathrm{~mm}$. All the four samples were cut into desired rectangular shape of size 0.4 inch $\times 0.9$ inch to fit into X-band waveguide for microwave measurements.

Table1. Composition used for RAMs preparation

\begin{tabular}{|l|l|}
\hline \multicolumn{1}{|c|}{ Sample code } & \multicolumn{1}{c|}{ Components } \\
\hline RAM-MW & $\mathrm{MWCNT}(30 \%)$ \\
\hline $\mathrm{RAM}-\mathrm{Ti}$ & $\mathrm{TiO}_{2}(30 \%)$ \\
\hline $\mathrm{R} A M-\mathrm{Ti} @ \mathrm{MW}$ & $\mathrm{TiO}_{2}$ coated MWCNT $(30 \%)$ \\
\hline $\mathrm{RAM}-\mathrm{Ti} @ \mathrm{MW} / \mathrm{Fe}$ & $\mathrm{TiO}_{2}$ coated MWCNT $(15 \%)+\mathrm{Fe}_{3} \mathrm{O}_{4}(15 \%)$ \\
\hline
\end{tabular}

\section{Characterization}

The samples were characterized by X-ray diffraction (XRD), which was conducted on a Rigaku Xray diffracrometer, ULTIMA III with $\mathrm{Cu} \mathrm{K}_{\alpha}$ radiation $(\lambda=1.5418 \AA)$ at a scanning rate of $1 \% \mathrm{~min}$. The $\mathrm{TiO}_{2}$ coated MWCNTs were analyzed by X-ray photoelectron spectroscopy (XPS) with a PHI ESCA spectrometer (Perkin-Elmer 5400), using $\mathrm{Mg} \mathrm{K}_{\alpha}$ radiation $(1253.6 \mathrm{eV})$ to reveal the change in surface characteristics of MWCNTs. The surface morphology and filler distribution of nanocomposites was analysed by scanning electron microscopy (SEM) which is governed by VEGA LSU, TESCAN instrument. For the SEM analysis to be done, the specimens were coated by a thin layer of gold for electrical conductivity. Transmission electron microscopy (TEM) analysis was carried out by a JEOL JEM2100 microscope, to analyse the dispersion state of the fillers in TPU matrix. Energy-dispersive X-ray spectroscopy (EDX) attached to TEM, while EDX analysis was performed to understand their chemical constituents. Microwave absorption study was done by using a two port vector network analyzer (ENA E5071C). Microwave absorption property of the prepared RAMs was measured by using Transmission Line method where, the material was placed inside an enclosed rectangular waveguide transmission line. Relative complex permittivity $\left(\varepsilon_{\mathrm{r}}\right)$ and permeability $\left(\mu_{\mathrm{r}}\right)$ was computed from the measurement of the reflected signal (S11) and transmitted signal (S21). Total filler percentage was maintained at $30 \%$ and the thicknesses of the RAMs were 
$2 \mathrm{~mm}$. Thermogravimetric analysis (TGA) was performed by using Dupont 2100 Thermogravimetric analyzer. The TGA measurements were conducted at a heating rate of $10^{\circ} \mathrm{C} / \mathrm{min}$ under Nitrogen atmosphere from 30 to $800^{\circ} \mathrm{C}$.

\section{Results and discussion}

\subsection{XRD analysis}

The XRD patterns of MWCNT, $\mathrm{TiO}_{2}$ coated MWCNT and $\mathrm{Fe}_{3} \mathrm{O}_{4}$ are shown in Figure $2 \mathrm{a}$ and $2 \mathrm{~b}$ respectively. MWCNT showed its characteristic peak (002) at $2 \theta=25.69$ whereas $\mathrm{TiO}_{2}$ coated MWCNT showed multiple peaks. Comparing with the standards it was found that the $\mathrm{TiO}_{2}$ formed was in anatase form. The most intense peak (101) for $\mathrm{TiO}_{2}$ coated MWCNT appeared at $2 \theta=25.38$. This XRD patterns were confirmed from the previously reported literature [34-35]. Hence, appearance of peaks corresponding to anatase $\mathrm{TiO}_{2}$ confirmed the
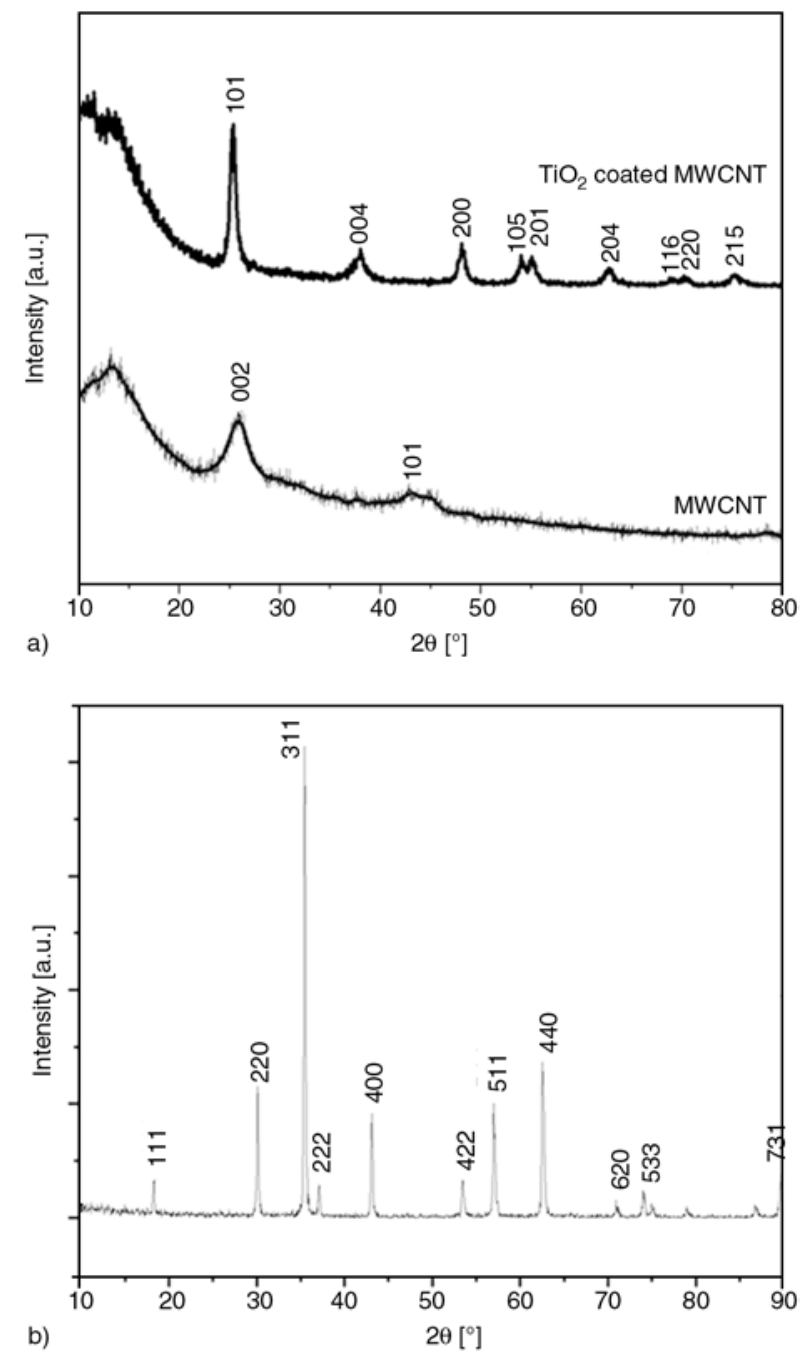

Figure 2. XRD analysis of (a) MWCNT and $\mathrm{TiO}_{2}$ coated MWCNT, (b) $\mathrm{Fe}_{3} \mathrm{O}_{4}$ formation of $\mathrm{TiO}_{2}$ during the sol gel coating process. The XRD pattern of $\mathrm{Fe}_{3} \mathrm{O}_{4}$ showed the characteristic peaks of $\mathrm{Fe}_{3} \mathrm{O}_{4}$ which are perfectly matched with
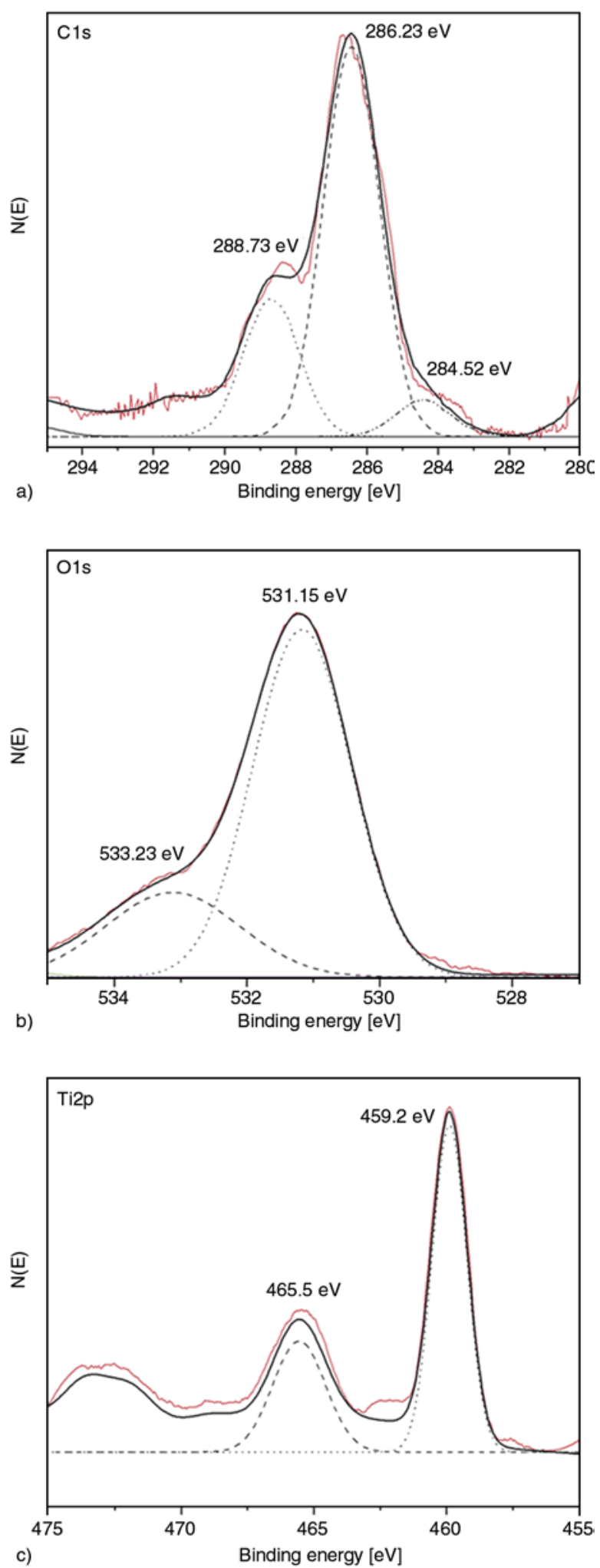

Figure 3. XPS Spectra of (a) C1s core level of modified MWCNTs, (b) $\mathrm{O} 1 \mathrm{~s}$ core level of modified MWCNTs and (c) Ti2p core level of modified MWCNTs 
JCPDS analysis (No-75-1610). Crystalline facets of $\mathrm{Fe}_{3} \mathrm{O}_{4}$ are (111), (220), (311), (222), (400), (422), (511), (440), (620), (533) and (731) respectively.

\subsection{XPS analysis}

XPS analysis was carried out to investigate the interaction between MWCNTs and $\mathrm{TiO}_{2}$. XPS spectrum of $\mathrm{C}, \mathrm{O}$ and $\mathrm{Ti}$ core levels of $\mathrm{TiO}_{2}$ coated MWCNT are shown in Figure $3 \mathrm{a}-\mathrm{c}$. The $\mathrm{C} 1 \mathrm{~s}$ XPS spectrum of $\mathrm{TiO}_{2}$ coated MWCNT showed two peaks at 284.52 and $286.23 \mathrm{eV}$ corresponding to $-\mathrm{C}-\mathrm{C}$ and $-\mathrm{C}-\mathrm{O}$ bonds respectively. The presence of peak at 284.52 indicated that there may be some uncoated MWCNTs or some part of the long MWCNTs remained uncoated. The presence of uncoated MWCNT in $\mathrm{TiO}_{2}$ coated MWCNT was also supported by TEM analysis (discussed later). Another peak was found at $288.73 \mathrm{eV}$ which corresponds to the $\mathrm{C}-\mathrm{O}-\mathrm{Ti}$ bond $[34,36]$. The peaks at 530.6 and $532.7 \mathrm{eV}$ of standard anatase $\mathrm{TiO}_{2}$ corre-

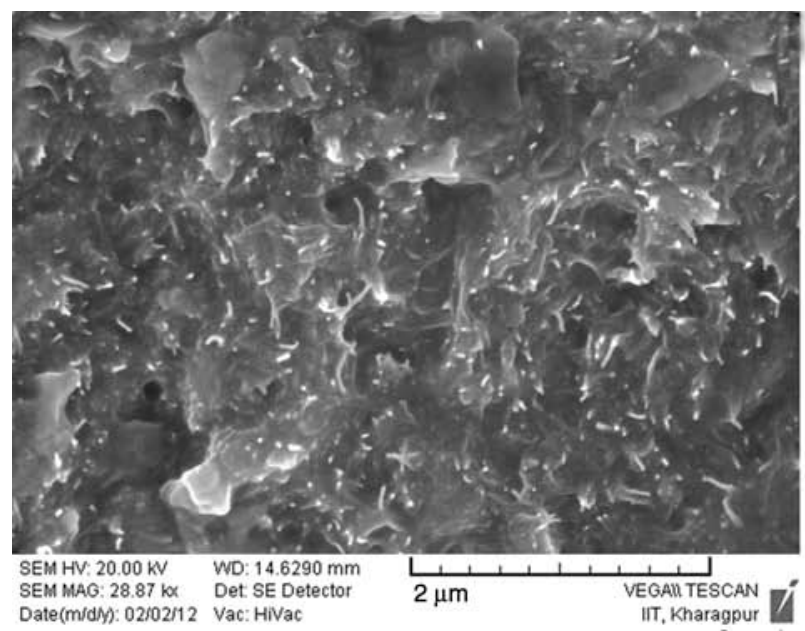

a)

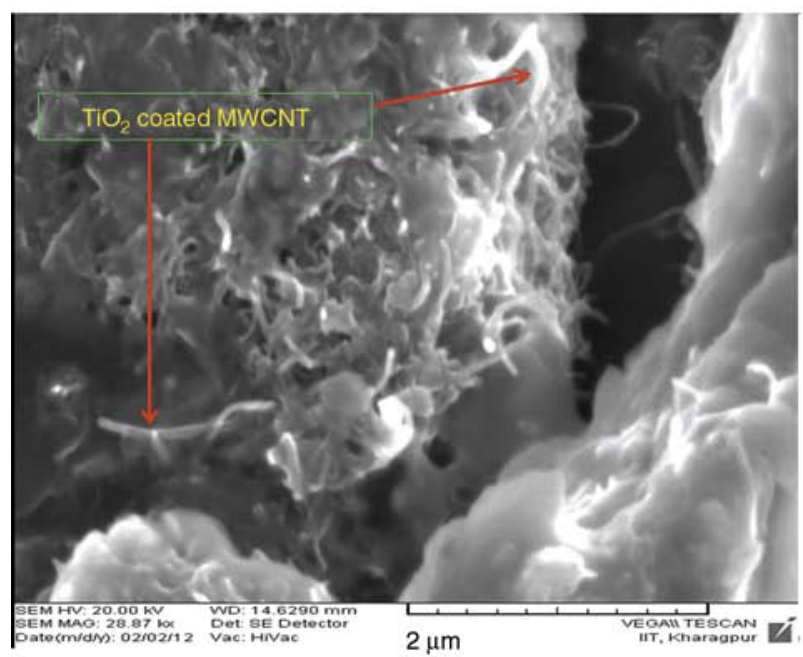

c) sponding to the lattice and surface oxygen, were shifted to 531.16 and $533.23 \mathrm{eV}$, respectively, in the O1s XPS spectrum of $\mathrm{TiO}_{2}$ coated MWCNT. This shift may be due to the bonding between oxygen and carbon present in MWCNT. The peaks present in the XPS spectrum of $\mathrm{Ti}$ (in $\mathrm{TiO}_{2}$ coated MWCNT) corresponds to 459.2 and $465.5 \mathrm{eV}$ for Ti2 $\mathrm{p}_{1 / 2}$ and Ti2 $\mathrm{p}_{3 / 2}$ respectively, which were shifted from the standard anatase $\mathrm{TiO}_{2}$ peaks (458.4 and $464.2 \mathrm{eV}$ ). Absence of $\mathrm{C}-\mathrm{Ti}$ direct bonding in the $\mathrm{C} 1 \mathrm{~s}$ spectra $(281.3 \mathrm{eV})$ and the shifting in the XPS spectrum of $\mathrm{Ti}, \mathrm{O}$ and $\mathrm{C}$ core levels confirmed the formation of $\mathrm{C}-\mathrm{O}-\mathrm{Ti}$ bond in $\mathrm{TiO}_{2}$ coated MWCNT.

\subsection{Morphological study}

SEM images of the nanocomposites are shown in Figure 4. Figure 4a demonstrated the dispersion of MWCNTs in TPU matrix of RAM-MW whereas; Figure $4 \mathrm{~b}$ shows the dispersion of $\mathrm{TiO}_{2}$ particles in TPU matrix (RAM-Ti). In both cases the fillers

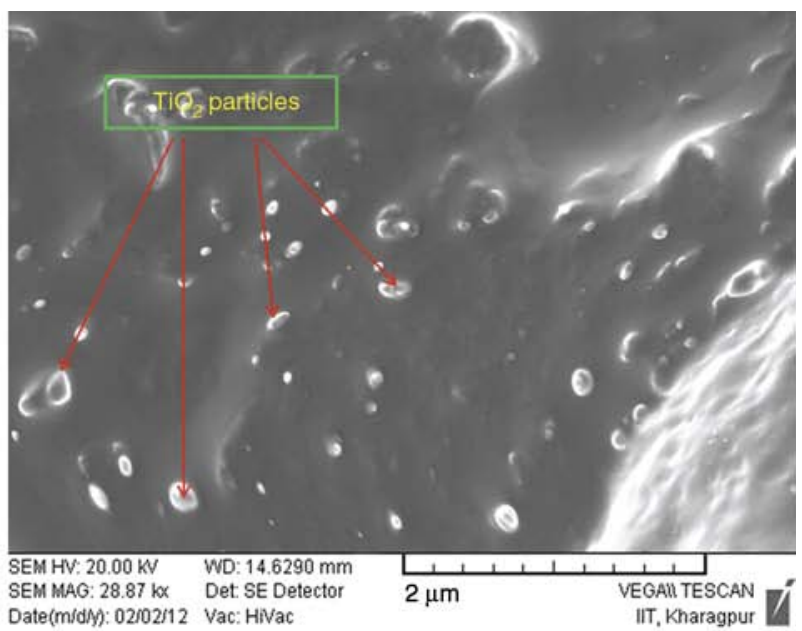

b)

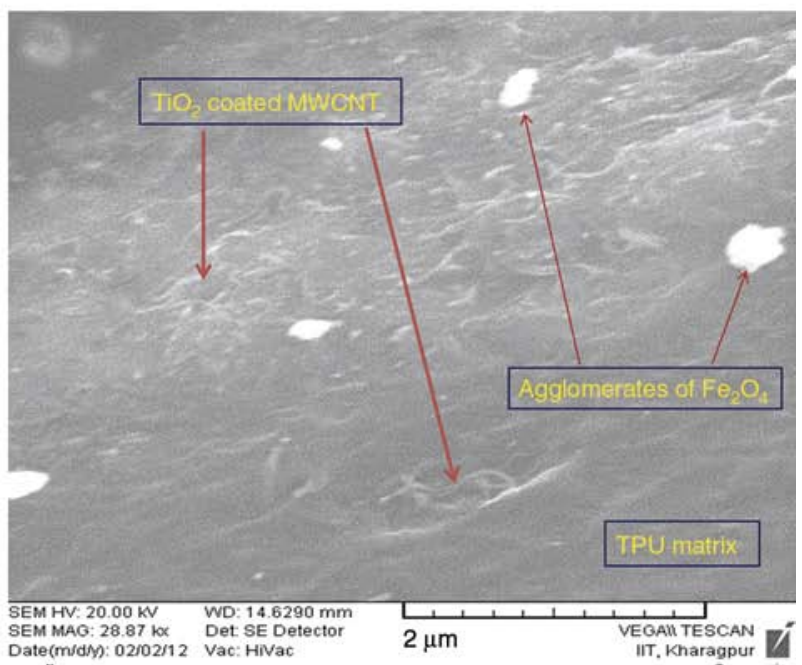

d)

Figure 4. SEM images of (a) RAM-MW, (b) RAM-Ti, (c) TiO 2 coated MWCNT and (d) RAM-Ti@MW/Fe 
were dispersed quite uniformly in the TPU matrix. Figure $4 \mathrm{c}$ shows the dispersion of $\mathrm{TiO}_{2}$ coated

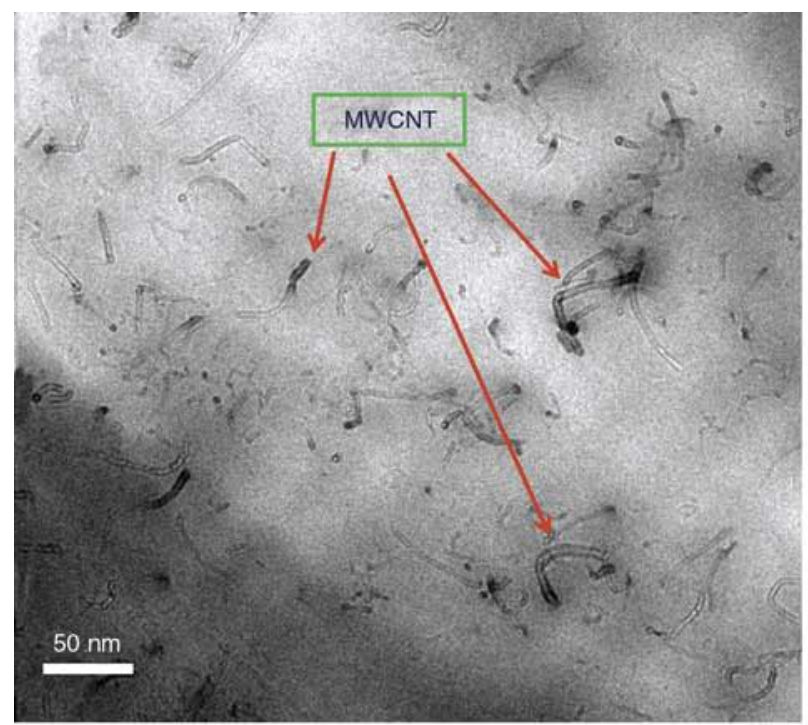

a)

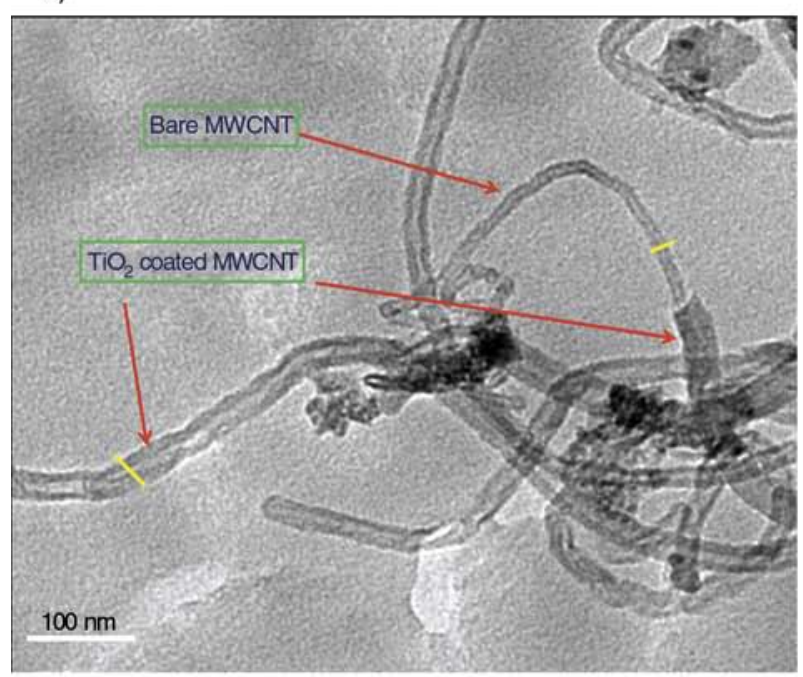

c)
MWCNTs in TPU matrix and the adhesion between the modified MWCNTs and TPU matrix was

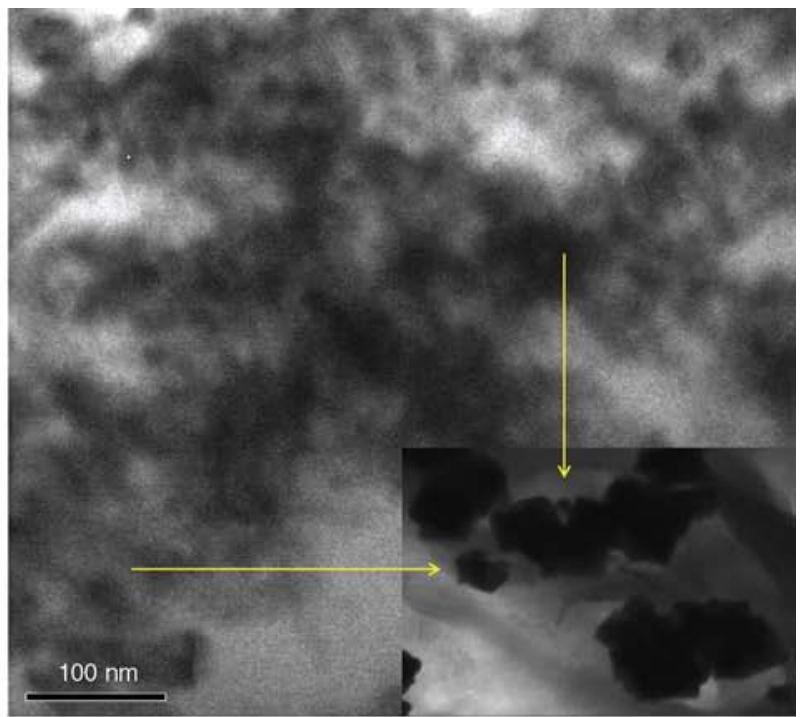

b)

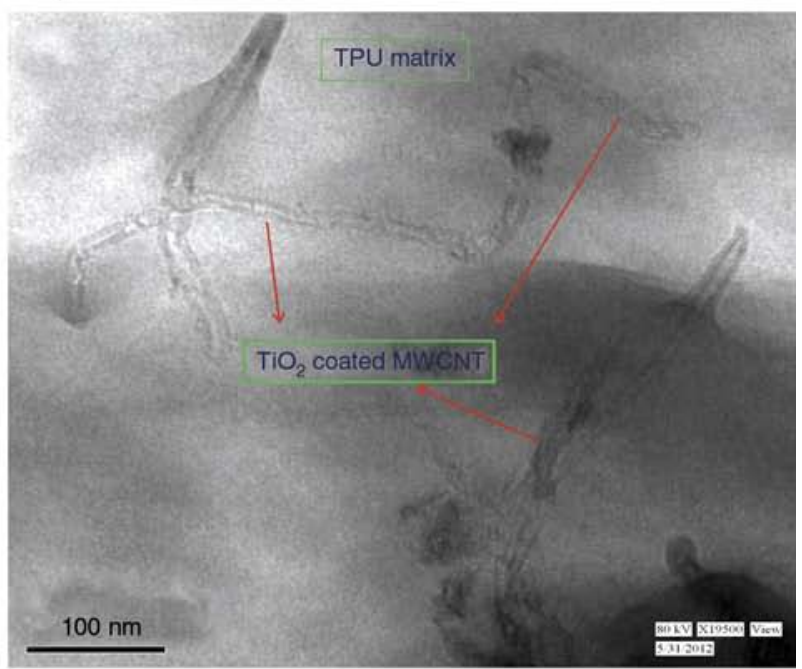

d)

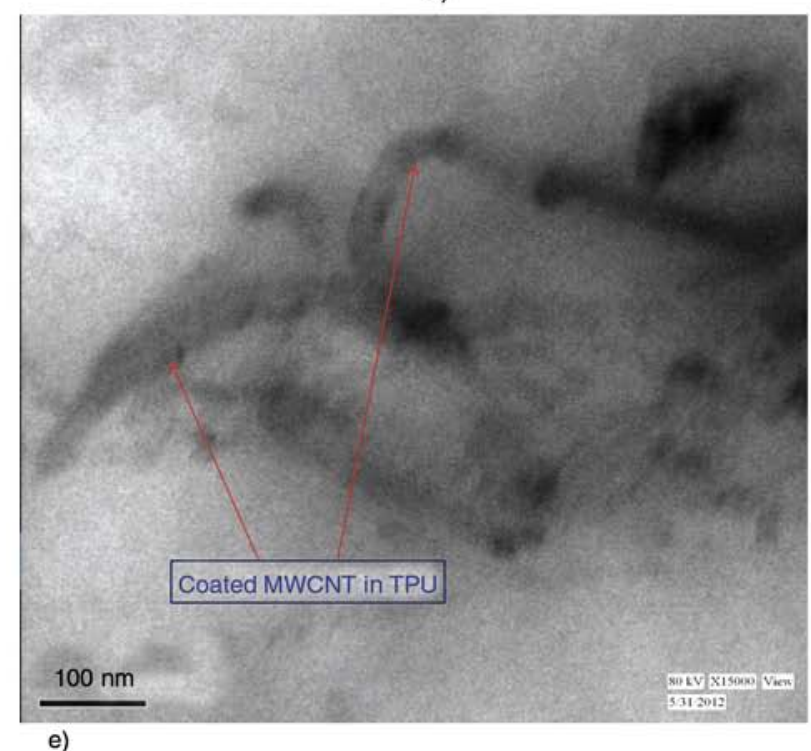

Figure 5. TEM images of (a) RAM-MW, (b) RAM-Ti, (c) TiO 2 coated MWCNT, (d) RAM-Ti@MW and (e) RAM$\mathrm{Ti} @ \mathrm{MW} / \mathrm{Fe}$ 
observed to be better than the unmodified MWCNTs. Figure $4 \mathrm{~d}$ shows the dispersion of $\mathrm{TiO}_{2}$ coated MWCNTs and ferrite particles in TPU matrix. To further confirm the dispersion of nanofillers in TPU matrix, TEM analysis was done and discussed below.

Figure 5a-e, shows the TEM images for all nanocomposites. Figure $5 \mathrm{a}$ and $5 \mathrm{~b}$ shows the dispersion of unmodified MWCNTs and $\mathrm{TiO}_{2}$, respectively, and further confirms the uniform dispersion of nanofillers in TPU matrix. Figure 5c shows the TEM image of $\mathrm{TiO}_{2}$ coated MWCNTs. It was observed that certain section of MWCNTs remain uncoated during the sol-gel coating process. It was also observed that the coated section $(\sim 40-45 \mathrm{~nm})$ has larger diameter as compared to uncoated portion
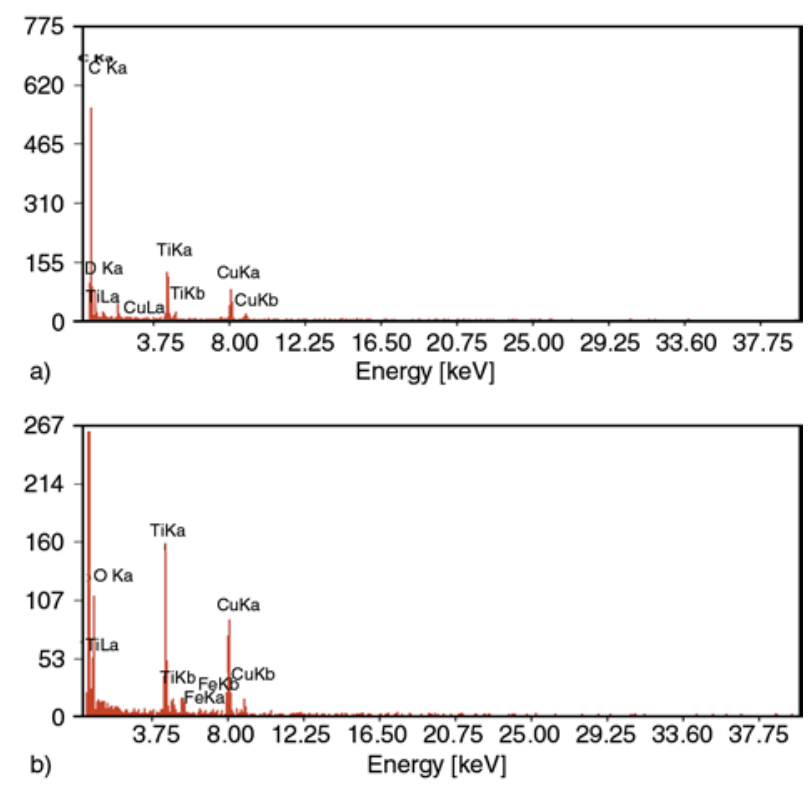

Figure 6. EDX study of (a) RAM-Ti@MW and, (b) RAMTi@MW/Fe

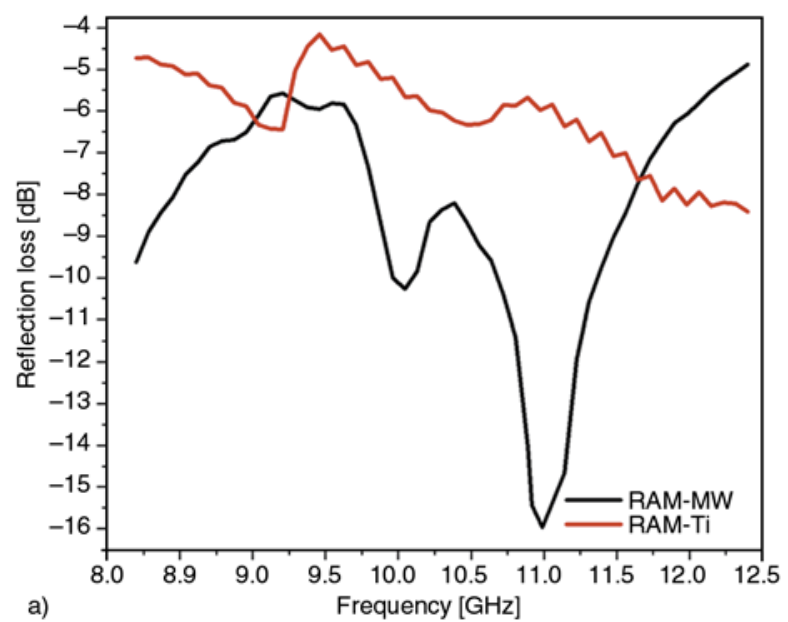

( 20-30 nm) which confirmed the coating of MWCNTs. Figure 5d showed the dispersion of $\mathrm{TiO}_{2}$ coated MWCNT in TPU matrix to confirm the formation of RAM-Ti@MW. Figure 5e refers the formation of RAM-Ti@MW/Fe. Development of RAM-Ti@MW and RAM-Ti@MW/Fe was further confirmed by EDX analysis which proved the presence of different element in the composite and shown in Figure 6. The presence of Ti and Fe peaks in the EDX analysis of RAM-Ti@MW and RAM$\mathrm{Ti} @ \mathrm{MW} / \mathrm{Fe}$ was due to the presence of $\mathrm{TiO}_{2}$ and $\mathrm{Fe}_{3} \mathrm{O}_{4}$, respectively.

\subsection{Microwave absorbing properties}

The microwave absorbing properties of the prepared RAMs were explained with the help of the characteristic electromagnetic parameters by using the Equation (1) and (2) [37], are related in this manner:

$$
Z=\sqrt{\frac{\mu_{\mathrm{r}}}{\varepsilon_{\mathrm{r}}}} \tanh \left[-j\left(\frac{2 \pi}{c}\right)\left(\sqrt{\mu_{\mathrm{r}} \varepsilon_{\mathrm{r}}}\right) f d\right]
$$

Reflection loss (in dB) $-20 \log \left[\left|\frac{z-1}{z+1}\right|\right]$

where $Z$ is the normalized input impedance with respect to the impedance in free space and reflection loss $(R L)$ is in decibels $[\mathrm{dB}], \mu_{\mathrm{r}}$ and $\varepsilon_{\mathrm{r}}$ are the relative complex permeability and permittivity of the absorber medium, $f$ and $c$ are the frequency of microwave in free space and the velocity of light, respectively and $d$ is the sample thickness. Figure 7 represents the reflection loss $V_{\mathrm{S}}$ frequency plot for all the four RAMs. The prepared RAMs showed the absorbing properties in a wide frequency range in the X-band region. RAM-MW, RAM-Ti, RAM-

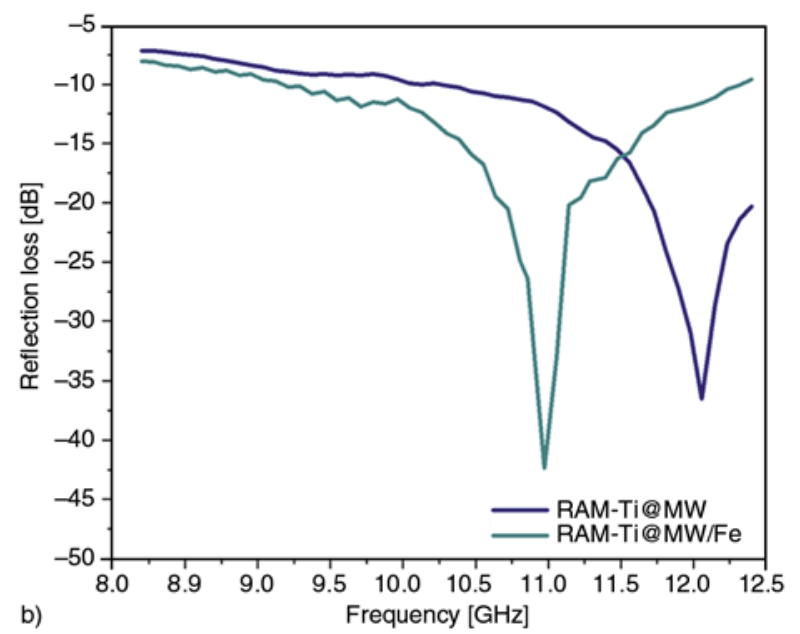

Figure 7. Reflection loss $V_{\mathrm{s}}$ frequency plot of (a) RAM-MW and RAM-Ti, (b) RAM-Ti@MW and RAM-Ti@MW/Fe 
Ti@MW and RAM-Ti@MW/Fe displayed the maximum reflection loss of $-16.03 \mathrm{~dB}$ at $10.99 \mathrm{GHz}$, $-8.4 \mathrm{~dB}$ at $12.4 \mathrm{GHz},-36.44 \mathrm{~dB}$ at $12.05 \mathrm{GHz}$ and $-42.53 \mathrm{~dB}$ at $10.98 \mathrm{GHz}$ respectively. Hence, from Figure $7 \mathrm{a}$, it was observed that the MWCNT based nanocomposite possessed superior microwave absorption property as compared to $\mathrm{TiO}_{2}$ based nanocomposite. RAM-Ti@MW and RAM-Ti@MW/Fe are most promising for RADAR application compared to other two. $\mathrm{TiO}_{2}$ coated MWCNT composite showed improved microwave absorbing properties than its individual components. Addition of magnetite $\left(\mathrm{Fe}_{3} \mathrm{O}_{4}\right)$ evidently enhanced the microwave absorbing properties of $\mathrm{TiO}_{2}$ coated MWCNT composite.RAM-Ti@MW showed the reflection loss of $-10 \mathrm{~dB}$ or more (absorption about $90 \%$ and above) by covering a frequency range from $10.01 \mathrm{GHz}$ to 12.4 GHz.RAM-Ti@MW/Fe also covered a long frequency range of $9.15-12.4 \mathrm{GHz}$ in the $\mathrm{X}$-band region, where the reflection loss value is $-10 \mathrm{~dB}$ or greater. According to the transmission line theory, [38] permittivity, permeability, sample thickness, and electromagnetic wave frequency can influence the reflectivity of electromagnetic wave which transmits through a medium. In this particular case, the frequency of radiation and thickness of the sample remained same for all the RAMs. So, to explain the variation in reflectivity, we studied the permittivity and permeability characteristics of the RAMs. The microwave absorption result of RAM-MW and RAM-Ti can be explained by considering their qualitative nature of conductivity. MWCNT is conducting whereas $\mathrm{TiO}_{2}$ is insulating. For good microwave absorption optimum conductivity of material is needed. Material with low conductivity may cause partial absorption of the microwave and highly conducting material transmits or reflects the wave without any absorption [39]. Since, the MWCNT has free electrons in its skeleton, so it can absorb energy and helps in attenuating as well [40]. Further the high surface area of MWCNT also may be a reason for its good microwave absorption behaviour. Now, if MWCNT and $\mathrm{TiO}_{2}$ involved in making a composite then it showed far better result than the individual component. This is may be due to the good combination between a conducting and an insulating material. $\mathrm{TiO}_{2}$ is a semiconducting material with low band gap energy of $3.23 \mathrm{eV}$, which also can assist the microwave absorption [41]. The addition of $\mathrm{Fe}_{3} \mathrm{O}_{4}$ in $\mathrm{TiO}_{2}$ coated MWCNT further helps in absorption and increases the reflection loss due to the loss initiated by a magnetic component. That is why RAM-Ti@MW/Fe becomes the superior microwave absorbing material among all. RAM-Ti@MW is only responsible for dielectric loss but RAMTi@MW/Fe showed its microwave absorption ability due to both dielectric and magnetic loss.

\subsection{Relative complex permittivity and permeability}

The possible mechanism of microwave absorption was investigated with the help of the real and imaginary part of complex permittivity $\left(\varepsilon^{\prime}, \varepsilon^{\prime \prime}\right)$ and permeability $\left(\mu^{\prime}, \mu^{\prime \prime}\right)$, where the real and imaginary part infers to the storage and loss part of the energy of a material respectively. Figure $8 \mathrm{a}$ and $8 \mathrm{~b}$ showed the real and imaginary parts of complex relative permittivity spectra for all four RAMs respectively. Figure 8c showed the real and imaginary parts of complex relative permeability for RAM-Ti@MW/Fe which contain a magnetic component. The values of real part of permittivity $\left(\varepsilon^{\prime}\right)$ for RAM-MW, RAM-Ti, RAM-Ti@MW and RAM-Ti@MW/Fe are 14.95$15.71,3.68-3.84,5.11-5.03$ and $6.78-6.56$ respectively. The values of imaginary part of permittivity $\left(\varepsilon^{\prime \prime}\right)$ for RAM-MW, RAM-Ti, RAM-Ti@MW and RAM-Ti@MW/Fe are 2.86-2.93, 0, 1.02-1.03 and 1.51-1.47 respectively. The lines for both real and imaginary part of permittivity remain almost constant throughout the whole frequency range in Xband region. The extent of polarization happening in the material is related to the real part of permittivity $\left(\varepsilon^{\prime}\right)$ and the imaginary part $\left(\varepsilon^{\prime \prime}\right)$ of permittivity is associated with the energy dissipated [42]. The different possible polarization mechanisms, which are helpful to describe the dielectric performance of the material, are ionic, electronic, orientational, and space charge polarization. In the microwave frequency range the active contribution can only be expected from orientational, and space charge polarization. The heterogeneity exists in the material is responsible for space charge polarization and the bound charges (dipoles) present in the material is answerable to the orientational polarization [43]. Hence, only orientational polarization may happen in RAM-Ti whereas, for other RAMs both orientational and space charge polarization can play a major role towards their dielectric performances. The values of real $\left(\mu^{\prime}\right)$ and imaginary part $\left(\mu^{\prime \prime}\right)$ of permeability for RAM-Ti@MW/Fe was determined 
and lie from 1.18 to 1.02 and 0.006 to 0.002 respectively. The real part of permeability decreases with increase in frequency whereas, the imaginary part of permeability $\left(\mu^{\prime \prime}\right)$ is almost zero and independent

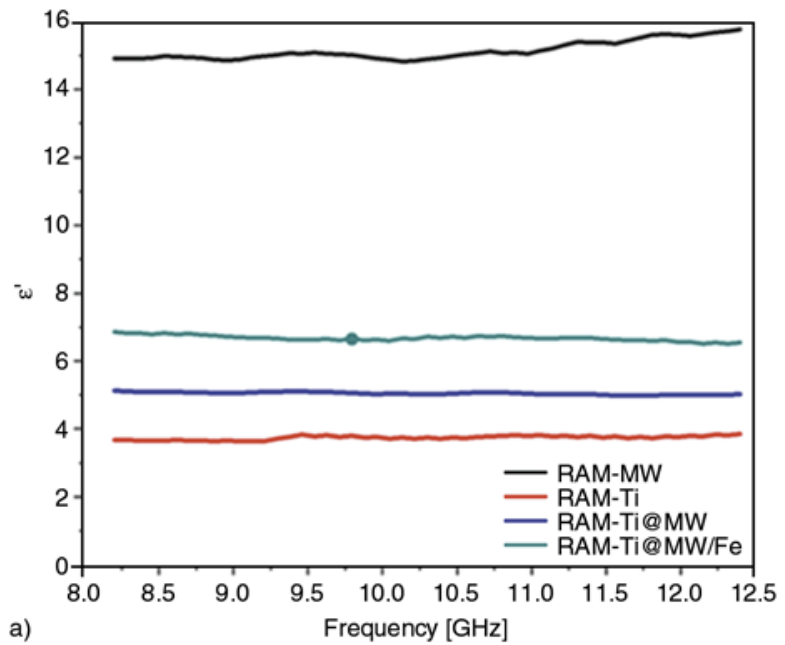

a)

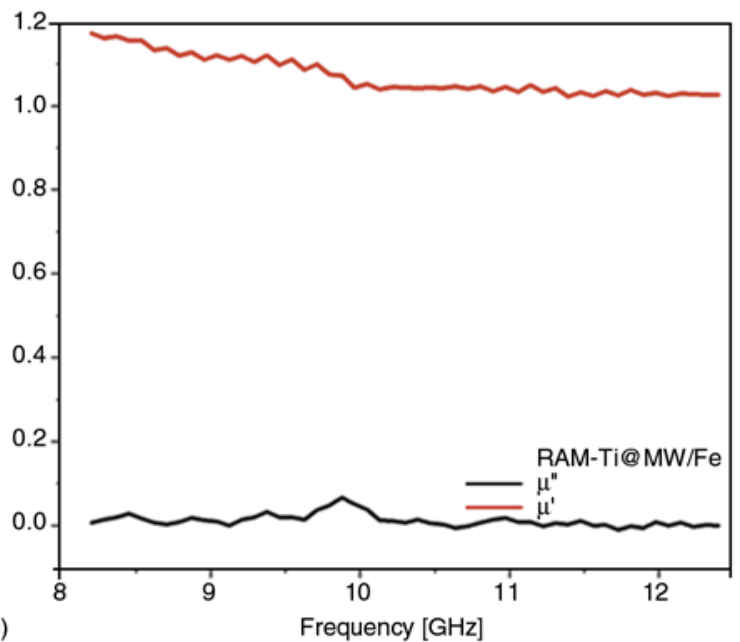

c) Frequency $[\mathrm{GHz}]$

on frequency. To understand the particular loss mechanism for each RAM, we have showed the loss tangent vs frequency plot in Figure $8 \mathrm{~d}$ and $8 \mathrm{e}$. The dielectric and magnetic loss tangents can be
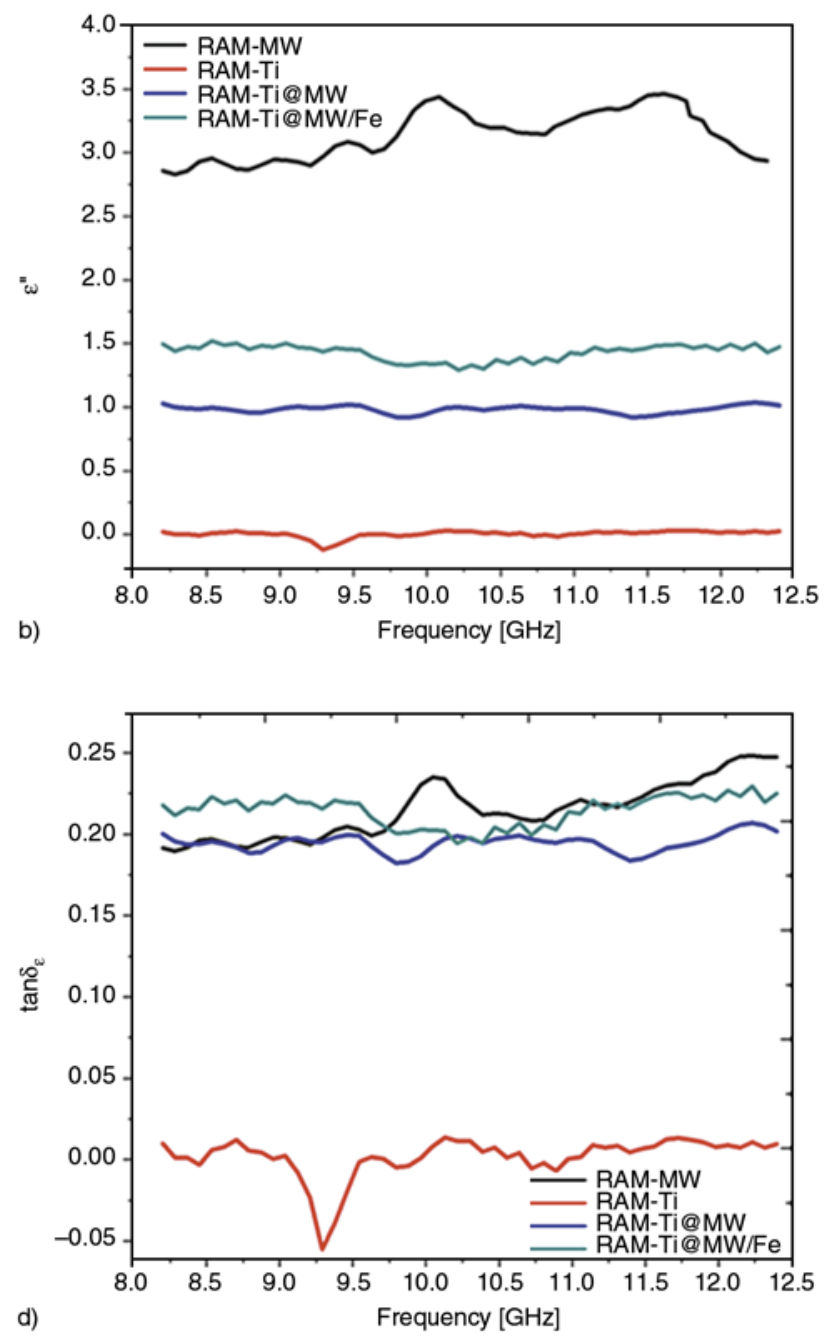

d)

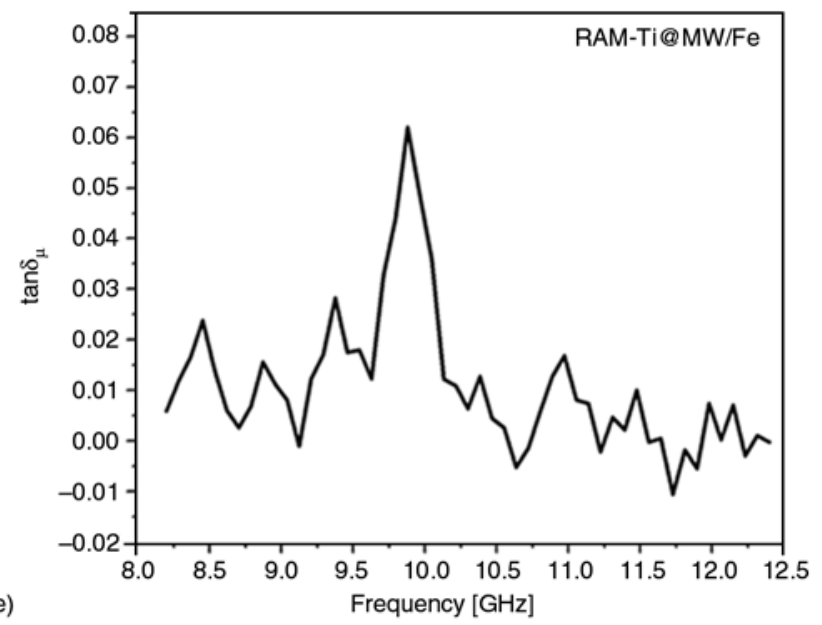

Figure 8. (a) Real $\left(\varepsilon^{\prime}\right)$ and (b) imaginary $\left(\varepsilon^{\prime \prime}\right)$ parts of relative complex permittivity of prepared RAMs, $(\mathrm{c})$ real $\left(\mu^{\prime}\right)$ and imaginary $\left(\mu^{\prime \prime}\right)$ parts of relative complex permeability of RAM-Ti@MW/Fe, (d) loss tangent of relative complex permittivity $\left(\tan \delta_{\varepsilon}\right)$ of the prepared RAMs and (e) loss tangent of relative complex permeability $\left(\operatorname{tann} \delta_{\mu}\right)$ of RAM-Ti@MW/Fe 
expressed as $\tan \delta_{\varepsilon}=\varepsilon^{\prime \prime} / \varepsilon^{\prime}$ and $\tan \delta_{\mu}=\mu^{\prime \prime} / \mu^{\prime}$, respectively. Figure $8 \mathrm{~d}$ showed the dielectric loss and Figure $8 \mathrm{e}$ showed the magnetic loss as a function of frequency. The plot showed that RAM-Ti@MW/Fe has both dielectric and magnetic loss part but the other RAMs showed mainly dielectric loss. This plots showed some negative values at different portion which might be due to the noise [44]. Addition of $\mathrm{Fe}_{3} \mathrm{O}_{4}$ particle may cause the hysteresis loss and eddy current loss which is responsible for magnetic loss [45]. Hence, the permittivity and permeability data supported the microwave absorption results of the prepared RAMs.

\subsection{Thermo gravimetric analysis (TGA)}

The thermal stability of the RAMs namely RAMMW, RAM-Ti, RAM-Ti@MW and RAM-Ti@MW/ Fe were analysed by TGA instrument, in nitrogenous atmosphere and shown in Figure 9. Thermally stable RAMs are required for its application in stealth technology. All the four RAMs showed similar behaviour in their TGA analysis but their thermal stabilities were found to be different. RAM$\mathrm{Ti} @ \mathrm{MW} / \mathrm{Fe}$ is comparatively most thermally stable material among all. The TGA analysis was performed from 30 to $800^{\circ} \mathrm{C}$. The thermal degradation was started after $330^{\circ} \mathrm{C}$ for all four RAMs and before $330^{\circ} \mathrm{C}$, the loss is insignificant. Up to $430^{\circ} \mathrm{C}$ the residual weight loss is only $15 \%$. After $430^{\circ} \mathrm{C}$, the loss becomes noticeable for all RAMs and at $500^{\circ} \mathrm{C}$ the loss reached to the maxima. From 500 to $800^{\circ} \mathrm{C}$, all showed a constant line but the extent of loss is different. Maximum weight loss for RAM-

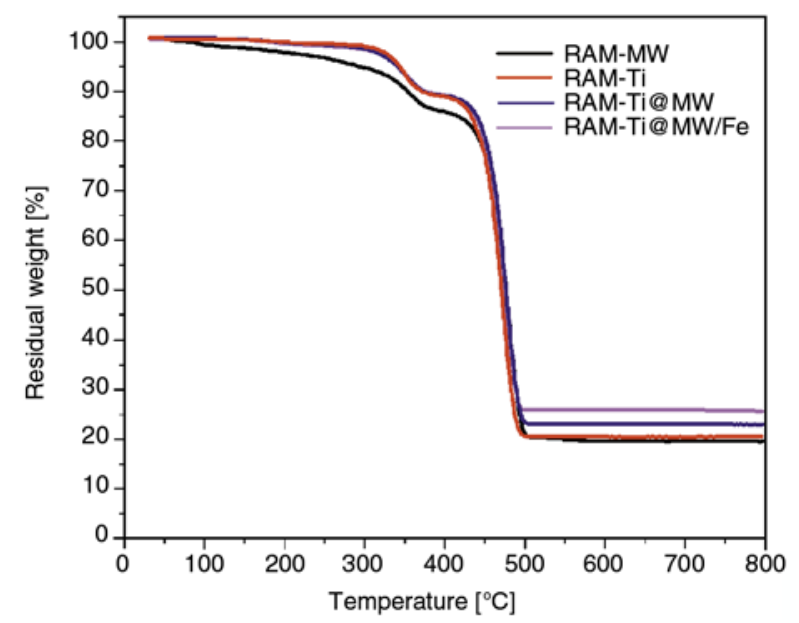

Figure 9. TGA plot of RAM-MW, RAM-Ti, RAM-Ti@MW and RAM-Ti@MW/Fe
MW, RAM-Ti, RAM-Ti@MW and RAM-Ti@MW/ $\mathrm{Fe}$ is $81,79,77$ and $74 \%$ respectively i.e. a decreasing trend which may be due to the increase in multiple bonding sites provided by different fillers present in the composite. Hence, all RAMs can be used up to $330^{\circ} \mathrm{C}$ effectively but RAM-Ti@MW/Fe is most thermally stable material. The highest thermal stability for RAM-Ti@MW/Fe was may be due to the better interaction between the components of the composite.

\section{Conclusions}

MWCNT based nanocomposites were prepared and characterized by different techniques to confirm their formation and then microwave absorption behaviour was discussed systematically. The maximum reflection loss achieved by RAM-Ti@MW/Fe was $-42.53 \mathrm{~dB}$ which was the result of optimal combination of both dielectric loss and magnetic loss. Dielectric loss mainly comes from dielectric material $\mathrm{TiO}_{2}$ and $\mathrm{MWCNT}$, whereas magnetic loss was mainly due to the $\mathrm{Fe}_{3} \mathrm{O}_{4}$. Other RAMs were also attractive but RAM-Ti@MW/Fe was the most promising candidate in $8.2-12.4 \mathrm{GHz}$ region. TGA measurement showed that RAM-Ti@MW/Fe was thermally more stable among all nanocomposites. Hence, $\mathrm{TiO}_{2}$ coated MWCNT and its nanocomposites were encouraging candidate as radar absorbing materials with usability in a wide frequency range maintaining strong absorption.

\section{Acknowledgements}

The authors are thankful to IIT Kharagpur. P.B. and S.S. are also thankful to Council of Scientific and Industrial Research (CSIR), New Delhi, India for providing the fellowship.

\section{References}

[1] Kakirde A., Sinha B., Sinha S. N.: Development and characterization of nickel-zinc spinel ferrite for microwave absorption at $2 \cdot 4 \mathrm{GHz}$. Bulletin of Materials Science, 31, 767-770 (2008).

DOI: $10.1007 / \mathrm{s} 12034-008-0121-2$

[2] Guo J., Wu H., Liao X., Shi B.: Facile synthesis of size-controlled silver nanoparticles using plant tannin grafted collagen fiber as reductant and stabilizer for microwave absorption application in the whole $\mathrm{Ku}$ band. Journal of Physical Chemistry C, 115, 2368823694 (2011).

DOI: $10.1021 / \mathrm{jp} 207194 \mathrm{a}$ 
[3] Liu Z., Bai G., Huang Y., Li F., Ma Y., Guo T., He X., Lin X., Gao H., Chen Y.: Microwave absorption of single-walled carbon nanotubes/soluble cross-linked polyurethane composites. Journal of Physical Chemistry C, 111, 13696-13700 (2007). DOI: $10.1021 / j p 0731396$

[4] Zhan Y., Meng F., Yang X., Zhao R., Liu X.: Solvothermal synthesis and characterization of functionalized graphene sheets (FGSs)/magnetite hybrids. Materials Science and Engineering: B, 176, 1333-1339 (2011). DOI: $10.1016 /$ j.mseb.2011.07.023

[5] Nanni F., Travaglia P., Valentini M.: Effect of carbon nanofibres dispersion on the microwave absorbing properties of CNF/epoxy composites. Composites Science and Technology, 69, 485-490 (2009).

DOI: $10.1016 /$ j.compscitech.2008.11.026

[6] Lv X., Yang S. L., Jin J. H., Zhang L., Li G., Jiang J. M.: Microwave absorbing characteristics of epoxy composites containing carbon black and carbon fibers (in Korean). Polymer-Korea, 33, 420-428 (2009).

[7] Wang Y. T., Wang C. S., Yin H. Y., Wang L. L., Xie H. F., Cheng R. S.: Carboxyl-terminated butadiene-acrylonitrile-toughened epoxy/carboxyl-modified carbon nanotube nanocomposites: Thermal and mechanical properties. Express Polymer Letters, 6, 719-728 (2012). DOI: 10.3144 /expresspolymlett.2012.77

[8] Das C. K., Bhattacharya P., Karla S. S.: Graphene and MWCNT: Potential candidate for microwave absorbing materials. Journal of Materials Science Research, 1, 126-132 (2012).

DOI: $10.5539 /$ jmsr.v1n2p126

[9] Singh V. K., Shukla A., Patra M. K., Saini L., Jani R. K., Vadera S. R., Kumar N.: Microwave absorbing properties of a thermally reduced graphene oxide/nitrile butadiene rubber composite. Carbon, 50, 2202-2208 (2012).

DOI: 10.1016/j.carbon.2012.01.033

[10] Yang Y. L., Gupta M. C., Dudley K. L., Lawrence R. W.: Novel carbon nanotube-polystyrene foam composites for electromagnetic interference shielding. Nano Letters, 5, 2131-2134 (2005).

DOI: $10.1021 / \mathrm{n} 1051375 \mathrm{r}$

[11] Qi X., Yang Y., Zhong W., Deng Y., Au C., Du Y.: Large-scale synthesis, characterization and microwave absorption properties of carbon nanotubes of different helicities. Journal of Solid State Chemistry, 182, 26912697 (2009).

DOI: $10.1016 /$ j.jssc.2009.07.036

[12] Zhu H., Lin H., Guo H., Yu L.: Microwave absorbing property of Fe-filled carbon nanotubes synthesized by a practical route. Materials Science and Engineering: B, 138, 101-104 (2007). DOI: $10.1016 /$ j.mseb.2006.12.018

[13] Liu X. G., Li B., Geng D. Y., Cui W. B., Yang F., Xie Z. G., Kang D. J., Zhang Z. D.: (Fe, Ni)/C nanocapsules for electromagnetic-wave-absorber in the whole $\mathrm{Ku}$ band. Carbon, 47, 470-474 (2009).

DOI: $10.1016 /$ j.carbon.2008.10.028
[14] Kim J-H., Kim S-S.: Microwave absorbing properties of Ag-coated $\mathrm{Ni}-\mathrm{Zn}$ ferrite microspheres prepared by electroless plating. Journal of Alloys Compounds, 509, 4399-4403 (2011).

DOI: $10.1016 /$ j.jallcom.2011.01.050

[15] Shi G. M., Zhang J. B., Yu D. W., Chen L. S.: Synthesis and microwave-absorbing properties of $\mathrm{Al}_{2} \mathrm{O}_{3}$ coated polyhedral Fe nanocapsules prepared by arc-discharge method. Advanced Materials Research, 299-300, 739-742 (2011).

DOI: $10.4028 / w w w . s c i e n t i f i c . n e t / A M R .299-300.739$

[16] Kavanloui M., Hashemi B.: Effect of $\mathrm{B}_{2} \mathrm{O}_{3}$ on the densification and magnetic properties of $\mathrm{Li}-\mathrm{Zn}$ ferrite. Materials and Design, 32, 4257-4261 (2011).

DOI: $10.1016 / \mathrm{j}$. matdes.2011.04.019

[17] Liu Z., Bai G., Huang Y., Ma Y., Du F., Li F., Guo T., Chen Y.: Reflection and absorption contributions to the electromagnetic interference shielding of singlewalled carbon nanotube/polyurethane composites. Carbon, 45, 821-827 (2007).

DOI: $10.1016 /$ j.carbon.2006.11.020

[18] Li N., Huang Y., Du F., He X., Lin X., Gao H., Ma Y., Li F., Chen Y., Eklund P. C.: Electromagnetic interference (EMI) shielding of single-walled carbon nanotube epoxy composites. Nano Letters, 6, 1141-1145 (2006).

DOI: $10.1021 / \mathrm{n} 10602589$

[19] Meng F., Zhao R., Zhan Y., Lei Y., Zhong J., Liu X.: Preparation and microwave absorption properties of Fe-phthalocyanine oligomer/ $/ \mathrm{Fe}_{3} \mathrm{O}_{4}$ hybrid microspheres. Applied Surface Science, 257, 5000-5006 (2011).

DOI: 10.1016/j.apsusc.2011.01.010

[20] Murugan M., Kokate V. K., Bapat M. S.: Synthesis, characterization and evaluation of reflectivity of nanosized $\mathrm{CaTiO}_{3}$ /epoxy resin composites in microwave bands. Bulletin of Materials Science, 34, 699-704 (2011). DOI: 10.1007/s12034-011-0184-3

[21] Che R. C., Zhi C. Y., Liang C. Y., Zhou X. G.: Fabrication and microwave absorption of carbon nanotubes/ $\mathrm{CoFe}_{2} \mathrm{O}_{4}$ spinel nanocomposite. Applied Physics Letters, 88, 033105/1-033105/3 (2006).

DOI: $10.1063 / 1.2165276$

[22] Kim S. K., Kim W-D., Kim K-M., Hwang C. S., Jeong J.: High dielectric constant $\mathrm{TiO}_{2}$ thin films on a $\mathrm{Ru}$ electrode grown at $250^{\circ} \mathrm{C}$ by atomic-layer deposition. Applied Physics Letters, 85, 4112-4114 (2004). DOI: $10.1063 / 1.1812832$

[23] Zhou W., Hu X., Bai X., Zhou S., Sun C., Yan J., Chen P.: Synthesis and electromagnetic, microwave absorbing properties of core-shell $\mathrm{Fe}_{3} \mathrm{O}_{4}$-poly(3, 4-ethylenedioxythiophene) microspheres. ACS Applied Materials and Interfaces, 3, 3839-3845 (2011).

DOI: $10.1021 / \mathrm{am} 2004812$ 
[24] Ni S., Wang X., Zhou G., Yang F., Wang J., He D. J.: Designed synthesis of wide range microwave absorption $\mathrm{Fe}_{3} \mathrm{O}_{4}$-carbon sphere composite. Journal of Alloys and Compounds, 489, 252-256 (2010).

DOI: $10.1016 /$ j.jallcom.2009.09.065

[25] Hudec B., Husekova K., Dobrocka E., Lalinsky T., Aarik J., Aidla A., Frohlich K.: High-permittivity metalinsulator-metal capacitors with $\mathrm{TiO}_{2}$ rutile dielectric and $\mathrm{RuO}_{2}$ bottom electrode. Materials Science and Engineering, 8, 012024/1-012024/4 (2010). DOI: $10.1088 / 1757-899 \mathrm{X} / 8 / 1 / 012024$

[26] Li C., Wang J., Wang X., Su W., Chen H., Zhuang D.: Nonlinear electrical properties of $\mathrm{TiO}_{2}-\mathrm{Y}_{2} \mathrm{O}_{3}-\mathrm{Nb}_{2} \mathrm{O}_{5}$ capacitor-varistor ceramics. Materials Science and Engineering: B, 85, 6-10 (2001). DOI: $10.1016 / \mathrm{S} 0921-5107(01) 00563-3$

[27] Grätzel M.: Solar energy conversion by dye-sensitized photovoltaic cells. Inorganic Chemistry, 44, 68416851 (2005).

DOI: $10.1021 / \mathrm{ic} 0508371$

[28] Waser R.: Nanoelectronics and information technology. Wiley-VCH Weinhein (2003).

[29] Lee C-S., Kim J., Son J. Y., Choi W., Kim H.: Photocatalytic functional coatings of $\mathrm{TiO}_{2}$ thin films on polymer substrate by plasma enhanced atomic layer deposition. Applied Catalysis B: Environmental, 91, 628633 (2009).

DOI: 10.1016/j.apcatb.2009.06.037

[30] Jia Y., Jiang Z. M., Gong X. L., Zhang Z.: Creep of thermoplastic polyurethane reinforced with ozone functionalized carbon nanotubes. Express Polymer Letters, 6, 750-758 (2012).

DOI: $10.3144 /$ expresspolymlett.2012.80

[31] Yuen S-M., Ma C-C. M., Lin Y-Y., Kuan H-C.: Preparation, morphology and properties of acid and amine modified multiwalled carbon nanotube/polyimide composite. Composites Science and Technology, 67, 2564 2573 (2007).

DOI: 10.1016/j.compscitech.2006.12.006

[32] Vatanpour V., Madaeni S. S., Moradian R., Zinadini S., Astinchap B.: Novel antibifouling nanofiltration polyethersulfone membrane fabricated from embedding $\mathrm{TiO}_{2}$ coated multiwalled carbon nanotubes. Separation and Purification Technology, 90, 69-82 (2012).

DOI: 10.1016/j.seppur.2012.02.014

[33] Yuen S-M., Ma C-M., Chuang C-Y., Hsiao Y-H., Chiang C-L., Yu A.: Preparation, morphology, mechanical and electrical properties of $\mathrm{TiO}_{2}$ coated multiwalled carbon nanotube/epoxy composites. Composites Part A: Applied Science and Manufacturing, 39, 119-125 (2008).

DOI: 10.1016/j.compositesa.2007.08.021

[34] Nayak G. C., Sahoo S., Rajasekar R., Das C. K.: Novel approach for the selective dispersion of MWCNTs in the Nylon/SAN blend system. Composites Part A: Applied Science and Manufacturing, 43, 1242-1251 (2012).

DOI: $\underline{10.1016 / \text { j.compositesa.2012.03.008 }}$
[35] Lee T. Y., Alegaonkar P. S., Yoo J-B.: Fabrication of dye sensitized solar cell using $\mathrm{TiO}_{2}$ coated carbon nanotubes. Thin Solid Films, 515, 5131-5135 (2007).

DOI: $10.1016 /$ j.tsf.2006.10.056

[36] Okpalugo T. I. T., Papakonstantinou P., Murphy H., McLaughlin J., Brown N. M. D.: High resolution XPS characterization of chemical functionalised MWCNTs and SWCNTs. Carbon, 43, 153-161 (2005).

DOI: 10.1016/j.carbon.2004.08.033

[37] Gang Y-R.: Electromagnetic properties and microwave absorption properties of $\mathrm{BaTiO}_{3}$-carbonyl iron composite in $\mathrm{S}$ and $\mathrm{C}$ bands. Journal of Magnetism and Magnetic Materials, 323, 1805-1810 (2011).

DOI: $10.1016 / \mathrm{j} . j \mathrm{mmm} .2011 .02 .013$

[38] Michielssen E., Sajer J-M., Ranjithan S., Mittra R.: Design of lightweight, broad-band microwave absorbers using genetic algorithms. IEEE Transactions on Microwave Theory, 41, 1024-1031 (1993).

DOI: $10.1109 / 22.238519$

[39] Li G., Xie T., Yang S., Jin J., Jiang J.: Microwave absorption enhancement of porous carbon fibers compared with carbon nanofibers. Journal of Physical Chemistry C, 116, 9196-9201 (2012).

DOI: $10.1021 / \mathrm{jp} 300050 \mathrm{u}$

[40] Wu J., Kong L.: High microwave permittivity of multiwalled carbon nanotube composites. Applied Physics Letters, 84, 4956-4958 (2004).

DOI: $10.1063 / 1.1762693$

[41] Xiao H-M., Liu X-M., Fu S-Y.: Synthesis, magnetic and microwave absorbing properties of core-shell structured $\mathrm{MnFe}_{2} \mathrm{O}_{4} / \mathrm{TiO}_{2}$ nanocomposites. Composites Science and Technology, 66, 2003-2008 (2006).

DOI: 10.1016/j.compscitech.2006.01.001

[42] Ohlan A., Singh K., Chandra A., Dhawan S. K.: Microwave absorption behavior of core-shell structured poly (3,4-ethylenedioxy thiophene)-barium ferrite nanocomposites. ACS Applied Materials and Interfaces, 2, 927-933 (2010). DOI: $10.1021 / \mathrm{am} 900893 \mathrm{~d}$

[43] Zhang Q., Li C., Chen Y., Han Z., Wang H., Wang Z., Geng D., Liu W., Zhang Z.: Effect of metal grain size on multiple microwave resonances of $\mathrm{Fe} / \mathrm{TiO}_{2}$ metalsemiconductor composite. Applied Physics Letters, 97, 133115/1-133115/3 (2010). DOI: $10.1063 / 1.3496393$

[44] Chiu S-C., Yu H-C., Li Y-Y.: High electromagnetic wave absorption performance of silicon carbide nanowires in the gigahertz range. Journal of Physical Chemistry C, 114, 1947-1952 (2010).

DOI: $10.1021 / \mathrm{jp} 905127 \mathrm{t}$

[45] Zhua Y-F., Zhang L., Natsuki T., Fu Y-Q., Ni Q-Q.: Synthesis of hollow poly(aniline-co-pyrrole)- $\mathrm{Fe}_{3} \mathrm{O}_{4}$ composite nanospheres and their microwave absorption behavior. Synthetic Metals, 162, 337-343 (2012). DOI: 10.1016/j.synthmet.2011.12.015 